\title{
"Young Slaves in the Land of Gambling" The State as a Helpless Viewer of the Struggle of the Youth with Gambling
}

\author{
Periklis Polyzoidis \\ Associate Professor \\ Department of Social Work \\ Democritus University of Thrace \\ 4, Polyfimou Street \\ 69132 Komotini, Greece
}

\begin{abstract}
While gambling is thriving worldwide, two worrying observations are made: first, the increase in the age span of gamblers from 33-55 years in the 1970s to 17-70 years in the present, and second, the unprecedent growth of online gambling, a field that young people feel very familiar with. We describe the general landscape of gambling in Greece and record both the intensity and the effect of this promotion on individuals aged up to 25 years. Primary data are drawn, on the one hand, by measuring the advertising time of gambling in the prime-time broadcasting of all national TV channels and, on the other hand, by a nationwide survey with a sample of 315 adults aged 25 years or less. The results are rather encouraging with regard to the present, but the possible effects of early exposure in future periods of the life cycle are still unknown.
\end{abstract}

\section{Walking in the valley of gambling: The stakes of the gambling industry and the "pass" of the state}

Gambling is a global and timeless phenomenon whose principles remain the same despite differences from region to region or across time periods. The gambling industry has been experiencing tremendous growth over the last three decades, and this trend is likely to prevail in the future.

\section{1 "Faites vos jeux": No state without a casino, no city without a derby}

People invented gambling games very early. Backgammon has a history of at least 4,000 years, and the first form of betting gambling seems to be similar to the contemporary "barbot" (casting dices). In the times when this kind of game was illegal, there were clubs where, in addition to the lookout man, was another person assigned with the duty to swallow the dices in the event of a police raid. Legislation on both land and online gambling varies from country to country and shapes the total value of the gambling industry in different ways. The global turnover is estimated at US $\$ 390$ billion for the year 2016, 50 billions of which was related to online gambling. Gaming spending per capita is $\$ 916$ in Australia, which has the world record, and is followed by Singapore, where the amount is \$892. The US, having Las Vegas as the hotspot, scores third with $\$ 505$ per capita spending.

The landscape in the US is mixed, as some states promote and others restrict gambling. In 2013, New Jersey legalized participation in online gambling, and by 2016, the turnover of the industry amounted to $\$ 16$ million. It is estimated that at least 65 million people are regular poker players in the US, while in 2007, more than $\$ 170$ billion were played in Las Vegas, bringing \$163 billion profit to players and seven billion to the casinos (Vintage Value Investing, 2018).

The gambling market is also large in Ireland, where per capita expenditure is approximately $\$ 500$. The corresponding expense in the United Kingdom that operates approximately 8,800 gaming stores with at least 170,000 gaming machines is \$377. China allows its citizens to participate only in state gambling. There is concern about the management of the former British colony of Macau, which has 38 large casinos and constitutes one of the world's most powerful gaming centers, with multibillion-dollar annual turnover (Vintage Value Investing, 2018). Malta is also a focal point for gambling because of its low taxation and overall gambling friendly policy.

\subsection{Poor man's destiny: Crisis-affiliated Greece in gambling vertigo}

In this paper, we consciously avoid even a brief account of the causes and characteristics of the crisis affecting Greece, as it is an exhaustively documented topic.

\footnotetext{
1“"Make your play". Roulette term in French signaling the starting of betting
} 
Unemployment combined with lack of interest and feelings of disappointment lead many Greeks to gambling agencies, where they can spend the entire day even when betting only a few euros. Gambling agencies in both the capital city and the provinces have become social meeting points, replacing traditional cafes. However, while until recently these spots were indeed very much like cafes, they currently incorporate many luxury and high-tech attributes that make the stay very pleasant. What is more, unlike the past, customers are no longer exposed to a common sight. This facilitates access and increases the risk of addiction (Inside story, 2019). The gambling market in Greece is multifaceted and large, especially if the illegal gambling turnover, which seems to be booming, is added.

In 2007, private gambling spending amounted to $€ 10$ billion or $4 \%$ of GDP. In the same year, only one game, "Let's Go Betting", made a turnover of $€ 2.14$ billion. During the three-year period 2008-2011, the main gambling institution (OPAP), with a share of $56 \%$, financed the Super League teams with $€ 250$ million. OPAP owns more than 4,000 gambling points across the country. According to the published budget for the financial year 2018, net pretax income amounted to $€ 1,547,015$, net income from games $€ 1,039,935$, and profits $€ 215,900$ before and $€ 145,301$ after taxes (Georgiou Club, 2018).

In 2016, gross revenues from the land gambling market amounted to $€ 1.6$ billion, or a little less than $1 \%$ of GDP, which is far from humble if we consider the struggle of the Greek state to reserve $3 \%$ of the GDP for education. The per capita expenditure followed the fluctuations in GDP, and in the same year, it amounted to $€ 628$. The total gross revenues of the land and internet markets amount to $€ 1.8$ billion. Per capita spending on land gambling is very close to the EU27 average, but the spending on online gambling is significantly lower ( $€ 24$ vs. $€ 41$ million). Government revenue from gambling in 2016 amounted to $€ 0.64$ billion and was distributed per provider as follows: OPAP 63.0\%, Casinos 28.2\%, Greek Lottery $8.1 \%$ and Horse Racing 0.7\% (Supervisory and Control Committee, 2017).

Along with the official market, however, there is an illegal market, the value of which is estimated at $30-40 \%$ that of the legal market. Sources of the Ministry of Culture, which is responsible for the gambling sector, say that the illegal market amounts to $€ 3.5$ billion, while market people estimate it at $€ 5.5$ billion; this implies a great loss of revenue for both the state and legitimate businesses that pay taxes and the insurance contributions of thousands of people. In the pre-crisis years, there were at least 120,000 illegal gambling machines in all neighborhoods throughout Greece, half of which were found in in Athens and Thessaloniki, and at least 23 online gambling sites.

However, in this country, hypocrisy prevails. When OPAP attempted to install 35,000 legitimate machines (VLTs), mostly within the already existing gambling points, there was strong resistance, although $80 \%$ of respondents in relevant surveys believe that the legalization of gambling will have more positive than negative effects (Texan, 2019). It is characteristic that on one day (Saturday, December 17, 2016), the Greek police invaded 21 mini-casinos and internet cafes throughout Greece, arrested 76 people and seized 171 terminals (Kourdisto portokali, 2017). In 2016, 347 offenses were detected, more than a thousand people were arrested and $€ 160,000$ were seized (EEDE, 2017). Nonetheless, it is difficult to discern whether the fluctuations are due to the growth of the sector or to the intensity of the controls.

\subsection{Fighting with the shadows: The asymmetric threat of online gambling}

As early as 1983, there was the possibility of telephone betting in football. It took approximately ten years to transfer this know-how to the internet. The first licenses for online casinos were granted shortly before 1994 to some small island complexes in the Caribbean. In 1996, InterCasino was founded, perhaps the oldest of its kind. By1998, the global online gambling industry had a turnover of \$834 million a year, which soon surpassed one million, and in 2005, it reached $\$ 12$ billion and continues to grow (Online Casino reports, 2019).

EU Member States realized early that they were unlikely to prevent players from betting online, and considering the fall in land casino turnover, they decided to legitimize the sector to regulate it, collect taxes, and limit illegality. The first major European country to legalize online games was the United Kingdom (2005), followed by France and Denmark. In 2009, Italy established partial legitimacy and received taxes of $€ 150$ million. Germany, Switzerland and Spain moved in the same direction. The European online market has been developing since then at a steady pace and has become the largest in the world; revenues reached $\$ 12.5$ billion in 2018, representing $42 \%$ of the global industry.

US has followed a different approach, perhaps to support the highly developed sector of land casinos. Thus, despite the great demand for online casinos and online poker, the framework is generally more restrictive. Nonetheless, there is no strict control over participation in games offered by online sites located abroad. The legally vulnerable link in the chain of online gambling is the banking organizations that facilitate transnational financial transfers for such purposes. The legal status for online gambling varies from country to country. In some countries, such as India and Singapore, gambling is booming, while the institutional framework, although officially restrictive, is in fact inadequate (Casinos, 2010). 
Online engagement is extremely easy, especially for young people who have a much greater ability to handle online media, in general. At the same time, confirmation of the actual age of the player is much more difficult online, as it is always possible to falsify the relevant data. Beyond that, the steps are simple and include tracking the destination (a simple search offers infinite possibilities), downloading and installing the software, and creating an account either with virtual money (for gaining familiarity and testing), or with real. After these steps, the possibilities are endless, as long as there is money to spend (Online Casinoreports, 2019b).

\subsection{The state as a rope walker in the Circus Maximus of gambling}

Under these circumstances, it is obvious that the state cannot limit, let alone prohibit, gambling for four obvious reasons:

- The size of the market is enormous not only because it generates enormous tax profits but also because it provides work for thousands.

- A ban on official gambling will lead mathematically to gigantic illicit gambling.

- Greece has neither the power nor the ability to restrict access to international gambling.

- Greece has no interest in banning land gambling. On the one hand, casinos attract tourists (especially Arabs and Turks). On the other hand, Greek players would find it very easy to turn to foreign markets (such as casinos just across the northern border of the country and in exotic destinations).

Thus, the only choice of the state is the strict regulation of the market. In 2004, a supervisory and control committee (SCC) that fully covers the complex range of modern gaming through the implementation of a series of laws was established. The Committee responds effectively to the great challenges of the sector, although both its operation and the regulatory framework are made up of approximately two dozen laws and individual regulations. The main task of the Commission is to regulate, supervise and control the sector to ensure legitimate and fair conduct, protect players, especially minors, and provide an environment where gambling is conducted legally, safely and without adverse economic and social repercussions.

In this context, no kind of gambling promotion should be directed to people under the age of 18 or aimed at enhancing the momentum of consumers towards gambling. In addition, advertisements should not make use of famous people or exploit the lack of consumer knowledge about the chances of success and profit. Furthermore, the messages should not imply that gambling can be a priority in life, a means of enrichment, or a way to escape financial difficulties. Participation in land and online games requires a minimum age of 21 , which must be proven by official identity documents.

\section{2. “Let me burn you Jermain, and I 'll heal you again”. Gambling addiction assistance by gambling operators}

In some cases, simple gambling for reasons of group or individual entertainment is converted into Gambling Disorder, a condition that belongs to the category of "impulse control disorders" and is characterized by constant and repeated persistence in gambling. The limits between normal and over-participation are not clear, and as with most addictions, the patient in the early stages believes that he can easily quit and that it is just a matter of choosing to go on. The majority of gambling profits come not from the large crowd of players but from the addicted players. Staying at the Las Vegas luxury hotels is very cheap, especially if compared with the high level of service, and so are the appetizing meals in the casinos, which are almost free of charge. A person who loses a little money in the casino is a loss rather than a profit. Although an addicted person may lose all his personal fortune and perhaps his family's estate, he will borrow money far beyond his capabilities and perhaps even steal money to continue gambling. At the end of the day, he will more than make up for the small loss caused by non-addicted players.

Casino marketing strategy includes very low prices, an attractive and luxurious atmosphere and appealing staff to attract as many players as possible. It is statistically certain that a firm percentage of the players will become addicted and indirectly pay the bills for everyone. Casinos block natural lighting in order for addicted players to lose both the sense of time and the physical adaption to the natural cycle between day and night. Players gradually avoid games that involve even minimal social interaction, such as blackjack or roulette, and they resort to slot machines, where they become part of the machine. The rhythm of the game is feverish, and the loss of large sums is almost certain (Schüll, 2014).

State regulation provides that any kind of gambling promotion has to list the telephone lines and the supporting services for gambling addiction. The message that is posted on all gambling-related communication media is "Gambling is only allowed for people over the age of 21. Frequent participation involves risk of addiction and loss of property. Support Line 1114». This phone number corresponds to the main state organization (KETHEA network), which is based in Athens and treats people who have problems with so-called "legal addictions", such as alcohol and gambling. 
Unlike smoking, drugs or alcohol, gambling addiction has no visible symptoms, and both the possible causes of the problem and the addiction signs are difficult to detect. In this approach, we deliberately avoid an extended reference to the reasons leading to gambling and gambling addiction. The problem is dependent on the interaction of a number of social and psychological factors that only specialized scientific staff could reliably explain further. Symptoms include changes in behavior, declining performance in the classroom or work, irritation, anxiety, poor quality of social life, isolation, declension, dysthymia, cyclothymic reactions, and increased anxiety. Other signs are disappearance of valuable items from home, repeated money borrowing, failure to respond to regular financial obligations, false excuses ("I lost my wallet", I was robbed in the middle of the street) and strong repulsion of any attempt to discuss the subject.

Slowly but steadily, the circle of dependence, which includes betting, anger about losing money, sadness, regeneration of hope (assisted by the "justified" need to restore the loss), and betting anew, becomes increasingly clear. Casual profits, the advertising of cases of people who earn enormous amounts of money and the ascertainment that financial damage is already at heights impossible to restore in any other way than winning the lottery, constantly worsen the situation and lead in a descending spiral, escape from which requires both great understanding and support from the family, on the one hand, and professional support by qualified personnel, on the other. The number of visits to rehabilitation centers has increased over the last few years, but it is difficult to say whether the increase is due to a corresponding increase in the number of addicts or to the reduction of prejudice and the parallel increase in the confidence in these centers.

Patients are accompanied in most cases by their spouses and partners and very rarely by their parents. The overwhelming majority regards addiction to legitimate games. The most frequent cases are the lottery games, followed by roulette, slot machines and derbies (NotoSport, 2018). Rehabilitation programs last from 18 to 24 months in classes of approximately 80 people (Axiotis, 2016). According to experts, most of the cases involve married men with an average age of 42 years, but in recent years, there has been an increase in the age range in both up and down directions.

This means that, on the one hand, the incidence of younger individuals aged 25 to 30 years is increased, and on the other, there is increased incidence of older people. The latter is a global observation, and it happens probably due to the increase in life expectation, which is also accompanied by an increase in illnesses associated with degenerative brain diseases. Elderly people diagnosed with pathological gambling are more likely to have poor mental and physical health, and $10 \%$ of them lose more money than they have at their disposal (Typos, 2014).

\section{3. "Repetition is the mother of all learning”. Empirical approach of gambling promotion through mass media}

The advertising landscape in Greece is shaped by the legal framework set by the European Parliament, which states that twelve-hour advertising from 6 am to $6 \mathrm{pm}$ may account for $20 \%$ of the daily program. The comprehensive institutional framework for gambling includes Law 1082/6.6.2014 "Regulation of commercial gambling communication issues". Among other things, it requires the application of filters to ensure that people under the age of 21 will be not exposed to gambling promotion material, a provision that proved very difficult to implement in practice (Netbet 2019).

Gambling promotion includes any kind of advertisement, and it comprises an extremely complex landscape that is difficult to capture and evaluate as a whole. For example, a TV commercial can be measured, as it is shown on specific channels, with a certain frequency and a specific duration. However, what about the logo of the sponsor of a football club, which appears on the shirt of the players, on the field, on television, on the internet, and on sports news? Furthermore, young people communicate mainly through the internet. Online ads can be displayed on search engines, blogs, articles, and sponsored posts on social media, and they can either allow for a direct online bet or provide information for a visit to a land-based gambling point. Different search engines provide different policies regarding the promotion of gambling.

Following the Chinese proverb, "It is better to light a candle than curse the darkness", and admitting our inability to analyze the advertising landscape of gambling as a whole, we focus on television advertising. More specifically, we attempt to record the duration, frequency and certain qualitative characteristics of this type of advertising in the primetime broadcast band (20:45 to 23:00) in the six nationwide television channels. According to what is described above, it is obvious that this is only a small fraction of the total advertising market; however, despite the rapid development of the internet, this fraction still has the highest pervasiveness.

We attempt to record both the direct and the indirect exposure (e.g., press conferences in the sport news on a site where the gambling sponsor data are visible). The observation period was June 1 and July 5, 2019, including Saturdays and Sundays. This period was chosen due to a lack of events that could affect the channel's advertising profile, such as major sporting events. The systematic record, although based on large data, leads to following five simple observations: 
1.Commercial advertising on public TV (ERT 1, ERT 2, ERT 3, ERTSports, Vouli) is very low and so is gambling advertising. Public TV in Greece though has an extremely low attendance rate.

2. Gambling advertising in the prime-time zone (21:00 to 23:00) of the private nationwide channels (ALPHA, ANT1, Macedonia, OPEN, SKAI, STAR) is highly frequent. There is at least one gambling advertisement in each one out of the three to five advertising intermissions. The pattern (with significant variations) is one commercial 60\%, two commercials $30 \%$, three commercials $10 \%$.

3. Gambling advertising is much more intensive when of ballots, Jackpots, or football matches are approaching. This is mainly on Fridays and Saturdays.

4. There seems to be no competition between different gambling choices. Each game has probably its own public.

5. There is not even the slightest indication that young people (let alone minors) are treated as possible target groups.

Regardless of the channel the viewer chooses, it is almost certain that he will be exposed to numerous gambling advertising messages. The legality of the messages cannot be contested, as it is obvious that the conditions imposed by the state are strictly implemented. Overall efficiency is difficult to record without costly and time-consuming procedures, but the fact that the general population's gambling is booming is a sign (though not proof because too many other factors contribute to this) that the advertisement indeed influences people. Some points worth mentioning are that the methods to increase effectiveness involve short, simple expressions, acting characters with which the gamblers can easily relate and strong repetition. A marketing expert could certainly add many other remarks. Throughout the entire observation time, there was not even the slightest evidence that young people under 25 were targeted, let alone minors. In the next section, we try to see how these observations are incorporated into the empirical field.

\section{4. “Leave me alone, old chap!": Empirical record of the attitude of young adults under 25 towards gambling and gambling advertisement}

In this effort to empirically record the extent of exposure of adults up to 25 years old to gaming promotion messages one the one hand and the effect of these messages on the other, we have addressed the largest possible sample. The sample does not represent the population in a scientific point of view, but it fulfils the requirements of the pilot research that we conduct since our ambition is limited to the detection of some trends rather than the formulation of general conclusions. We used a 22-question questionnaire that was channelled electronically, with technical features and a format that the target group may find attractive. Our initial desire to include minors was unable to be acted upon due the very strong protection that the institutional framework provides for this special group. We must confess that we were relieved rather than disappointed.

The invitation to participate in the survey had the form of an email, which, in addition to a brief description of the survey and the active electronic link to the questionnaire, contained additional links relating to the certification of the researcher's identity, contact details and assurance of anonymity. There was also a plea for further forwarding. In total, 309 people responded to that call. The relatively low response rate in relation to the total number of inviting messages was a first indication that gambling is not a high priority for this target group. It is notable that approximately $70 \%$ of the responses were made through mobile phones, the medium that is particularly popular among young people, while in similar studies targeting the general population, this number is usually extremely low.

Concerning frequency, only $3.3 \%$ of the respondents bet a few times a week, while the vast majority never bet $(24.8 \%)$ or bet once a year $(63.5 \%)$ (Table 1). Most people either participate for fun $(53.9 \%)$ or spend some time betting (13.5\%), but $17 \%$ seek wealth, and a worrying $12.2 \%$ try to cover basic economic needs by betting. Respondents consider that the amount they spend on gambling is insignificant $(91.3 \%)$ or mediocre $(6.9 \%)$ compared to the money they have at their disposal. Online casino and betting sites visited tend to zero (38.2\% "once in a year" and almost everybody else "never"). The lack of a "professional" attitude also arises from the fact that only $14.8 \%$ state that they know exactly the chances of winning, while the remaining $85.2 \%$ know little (42.2\%) or nothing (43\%). This low participation rate is estimated to remain constant, as only $3.9 \%$ state that their future participation in gambling will increase "somewhat or much", while $64.9 \%$ state that it will remain stable, $13 \%$ that it will drop and $18.2 \%$ that it will stop. 


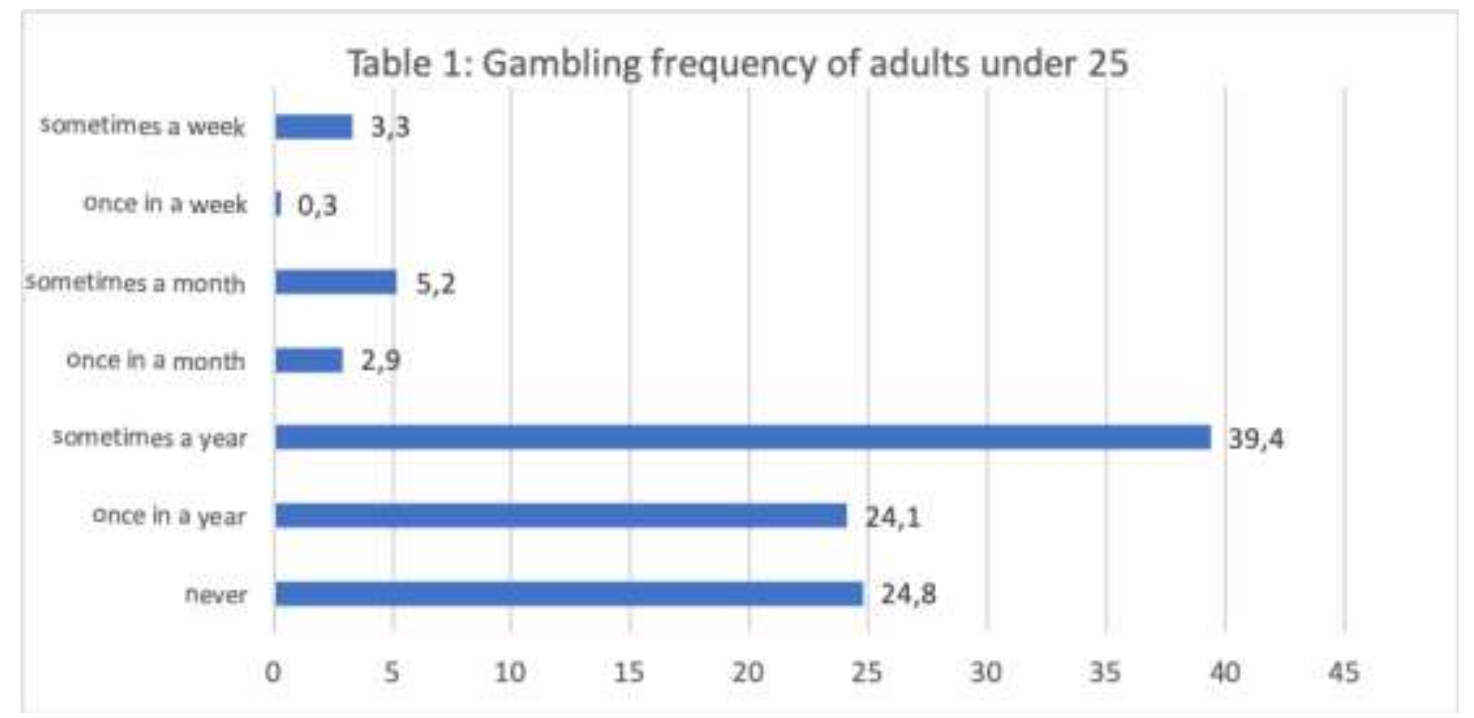

Concerning the profile of respondents, a relatively high percentage (42\%) started gambling before the age of 18 , while a similar percentage (46.7\%) reported that at least one parent was a gambler. People who state that they participate in gambling also state that they discuss gambling issues with friends rarely $(24.8 \%)$, sometimes $(17.8 \%)$, occasionally (7.4\%) or always $(7.4 \%)$ (Table 2$)$.

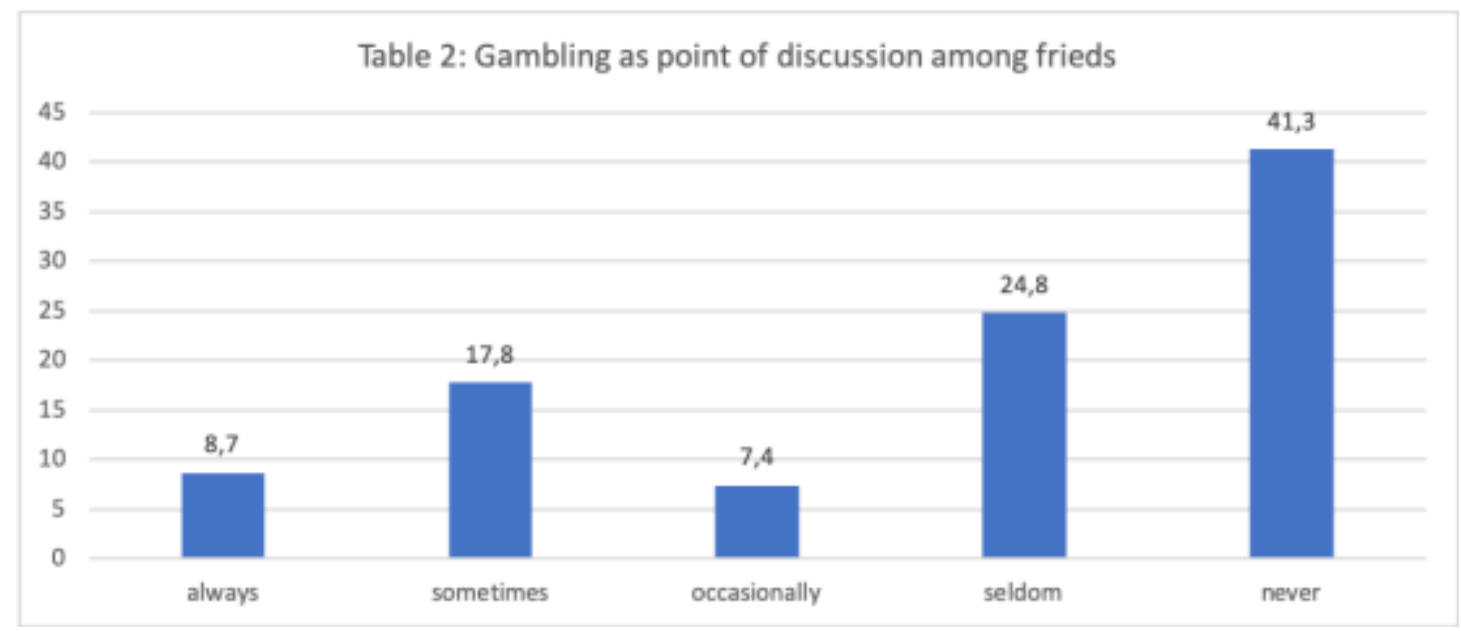

The exposure of the target group to gambling-promoting actions is continuous. The vast majority (65.5\%) see posters that advertise gambling frequently $(29.3 \%)$, sometimes $(28.3 \%)$ or continuously $(7.9 \%)$, while only approximately onethird of them say they see such posters rarely $(24.3 \%)$ or never $(10.2 \%)$. The fact, however, that the respondents live in similar surroundings makes us think that what they state is not the actual frequency of encountering a poster but rather the frequency of perception of such posters. In the same sense, people state that they hear gambling advertisements broadcast on the radio sometimes $(31.9 \%)$, often $(24.4 \%)$ or continuously $(4.6 \%)$, and fewer hear such advertisements rarely $(26.4 \%)$ or never $(12.7 \%)$. Worst is the situation in the television, where only $10.8 \%$ state that pro-gambling advertisements are rare $(8.5 \%)$ or non-existent $(2.3 \%)$, while the vast majority, almost nine out of ten, state that such advertisements appear continuously (20.3\%), often (44.6\%) or at least a few times a day (24.3\%) (Table 3). 


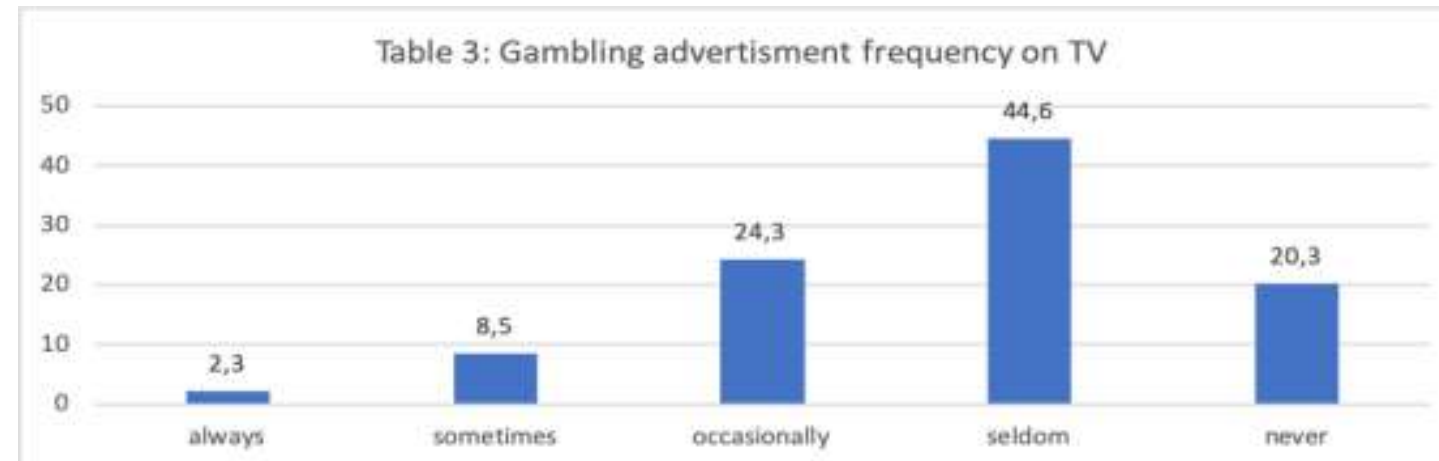

According to the respondents, the presence of gambling advertisements is even more pronounced in their favorite medium of communication, the internet: only $6.4 \%$ consider it rare $(5.2 \%)$ or non-existent $(1.3 \%)$, while the remaining $93.6 \%$ state that the presence is occasional $(14.7 \%)$, frequent $(42 \%)$ or continuous $(36.8 \%)$. The network of land gambling spots is very dense. Thus, for $64.1 \%$, the closest spot to home, workplace or educational institution is in visual view (14.4\%) or within walking distance $(64.1 \%)$, while only $11.1 \%$ state that it is far away or that they do not know where it is $(10.5 \%)$. In the same sense, $88.8 \%$ of responders walk past a gambling point during their regular commute $(34.6 \%)$ or at least frequently $(54.2 \%)$ and only $6.2 \%$ rarely or never $(2 \%)$ (Table 4$)$.

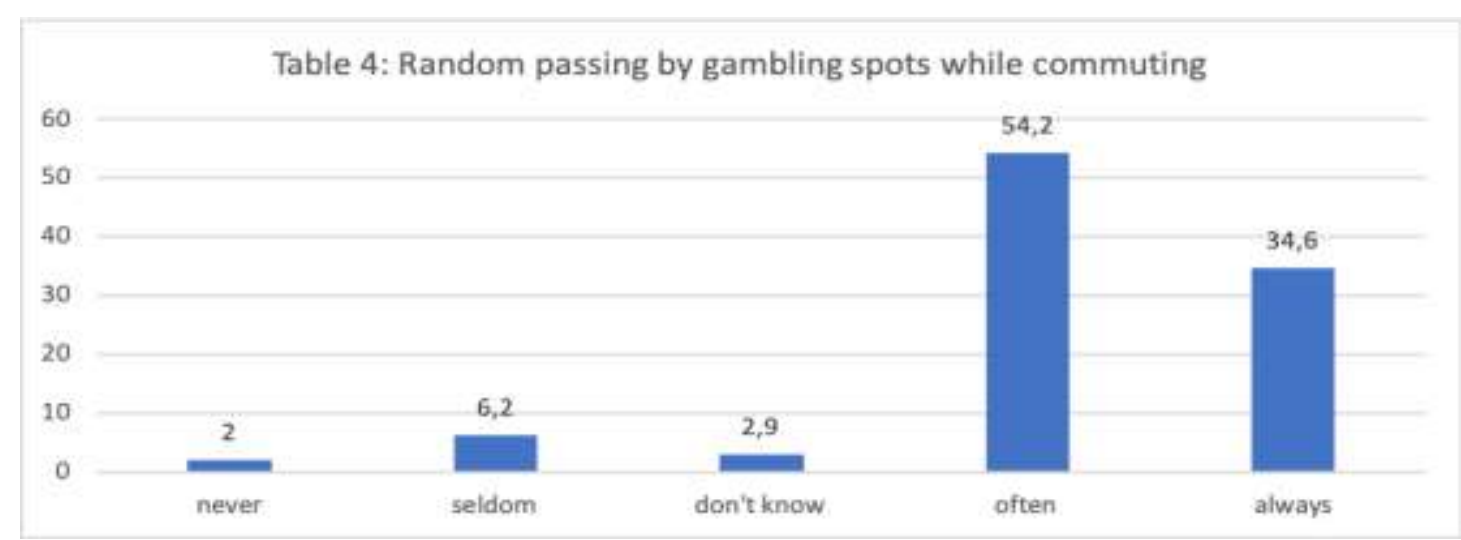

Despite the existence of extensive distribution and promotion networks, the impact of gambling on the target group remains extremely limited. Thus, only $9.4 \%$ of respondents say that gambling ads motivate them to gamble, while $50.5 \%$ state that there is no impact at all. Similar are the answers to whether gambling advertisements remind people to gamble, as $55.6 \%$ state that they see no influence in this direction, $28 \%$ that there is some influence, and only $12.8 \%$ that the influence is strong. Among gamblers, gambling ads have little effect on gambling frequency, as only $7.2 \%$ state that there is clearly an effect, $18.7 \%$ state that there may be some effect and $69.8 \%$ that there is no effect at all (Table 5).

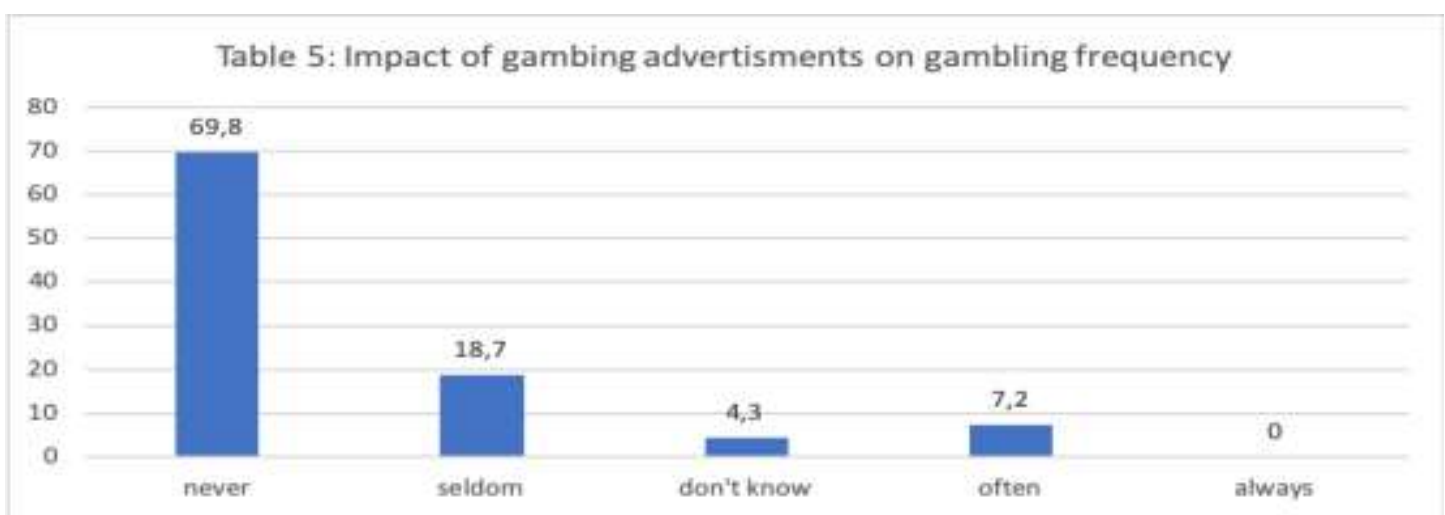

Regarding the content of the advertisements in particular, viewing cases of winners of millions of Euros has very little effect on gambling behavior. Only $0.7 \%$ state that they are strongly motivated, $22,2 \%$ moderately, $43.5 \%$ slightly and $30.1 \%$ not at all. Announcements of the great amounts of money that are at stake also have no significant effect. 
Approximately two out of ten state that the influence is strong, while the influence is small for $36.8 \%$ and non-existent for $37 \%$. Instead of focusing on profit possibilities, young adults seem to pay more attention to the warning messages that "participation may lead to addiction and loss of property". The vast majority state that the demonstration of these messages reduces their willingness to gamble strongly (20.2\%), moderately (21.2\%) or little (19.9\%) and only one out of four that there is no impact.

\section{Conclusion: Can you teach an old dog old new tricks?}

Gambling is here to stay forever. The efforts of states to restrict or ban it are futile because the consequences would be the switch to illegal and online gambling and the outbreak of outbound gambling tourism. Acknowledging this reality, states tolerate gambling and try to introduce regulatory measures to protect the public, on the one hand, and collect taxes, on the other. Greece is no exception. The legal framework is adequate; however, illegal gambling cannot be fully controlled. The density of gambling spots and the intensity of advertisements raise the danger of spreading the idea that gambling is a normal (or even a "must do") everyday behavior.

Despite the intense promotion of gambling, the influence on young people remains very small. Both frequency of gambling and the amounts spent are low and do not raise concern. This does not imply that the $3.3 \%$ who gamble every week or the $12.2 \%$ who gamble to meet economic needs do not require exhaustive investigation and immediate response. Gambling promotion has no significant effect on the betting behavior of the large majority. In contrast, young adults carefully consider the mandatory accompanying messages referring to the risk of addiction and loss of property.

The fact that the empirical data are rather optimistic does not mean that everything is under control. For a certain segment of the population, gambling functions like religion. Little children who go with their mom to church have complete ignorance of the effect of the service on them. However, they return to the church at mature ages, motivated to a greater or lesser extent by the early impressions they have unconsciously acquired. Although it is difficult to prove that something similar happens with gambling, it is obviously equally difficult to prove the opposite. The very high percentage of mature gamblers among the general population advocate for the first case.

\section{References}

Axiotis, A. (2016). Struggling with the monster of gambling. https://www.vice.com/gr/article/9a5kv5/ethismenoi-stontzogo[access 1/7/2019]

GeorgiouClub (2018). The multinational industry of gambling and the control over world sports. https://www.georgiouclub.gr/oi-polyethnikes-toy-tzogoy-kai-o-elegchos-toy-pagkosmioy-athlitismoy/ [access $4 / 7 / 2019]$

Insidestory (2019). The dangerous attraction of gambling under the conditions of financial crisis. https://insidestory.gr/article/tzogos-stin-krisi [access 1/7/2019]

Kazinopolis (2010). The European Gambling industry is the biggest in the world. http://casinopolis.org/i-eiropaikibiomixania-tzogou-einai-i-megaliteri-ston-kosmo/ [access 1/7/2019]

Kourdistoportokali (2017). The dark side of illegal gambling. https://kourdistoportocali.com/news-desk/o-skotinoskosmos-tis-viomichanias-tou-paranomou-tzogou/ [access7/7/2019]

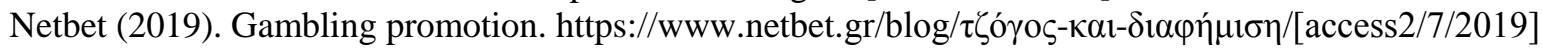

NotoSport (2018). Gambling addiction: Indications, treatment, rehabilitation. The experts view. https://notosport.eleftheriaonline.gr/pame-stoixima/item/23195-ethismos-ston-tzogo-endeixeis,-antimetwpish,apexarthsh-syzhthsh-me-toys-eidikoys [access6/7/2019]

Online Casinoreports $(2019 \alpha)$.The history of online gambling. http://www.onlinecasinoreports.gr/guides/history-ofonline-gambling.php [access5/7/2019]

Online Casinoreports (2019ß). The real world of online gambling.http://www.onlinecasinoreports.gr/guides/onlinegambling-facts.php[access3/7/2019]

Schüll, N. D. (2014). Addiction by Design: Machine Gambling in Las Vegas. Princeton University Press.

Supervisory and Control Committee (2017). 2016 Report. https://www.gamingcommission.gov.gr/images/enimerosi/ektheseis-pepragmenon/AnnualReport2016GR.pdf [access $8 / 7 / 2019$ ]

Typos(2014). Why is the majority of gamblers old and sick?;http://www.typos.com.cy/cat/13/article/6888 [access $1 / 7 / 2019]$

Vintage Value Investing (2018). Global gambling industry: the state of play in 2018. https://vintagevalueinvesting.com/global-gambling-industry-the-state-of-play-in-2018/ [access 1/7/2019]

Yfantis, P. D. (2019). The growth of illegal gambling. http://www.enet.gr/?i=news.el.article\&id=223489 [access4/7/2019] 